\title{
VIENERIŲ METŲ ŠAUDYMO PISTOLETU RENGIMO IR PARENGTUMO MODELIŲ SĄSAJOS YPATUMAI
}

\author{
Vaida Gulbinskienė, Antanas Skarbalius \\ Lietuvos kūno kultūros akademija, Kaunas, Lietuva
}

\begin{abstract}
Vaida Gulbinskienè. Lietuvos kūno kultūros akademijos edukologijos krypties doktorantė. Sporto technologijų katedros asistentė, Sportininku rengimo valdymo laboratorijos jaunesnioji mokslo darbuotoja. Mokslinių tyrimų kryptis — sportininkų rengimo modeliavimas.
\end{abstract}

\section{SANTRAUKA}

Didelio meistriškumo šauliu rezultatams pasiekti ypatinga reikšmę turi gerai parengta ir veiksmingai taikoma kiekvieno rengimo etapo programa, atitinkanti šaulio individualumus. Nuolatine krūviu ir rezultatu pokyčiu analizè leidžia valdyti sportini rengima. Visgi sportininku parengtumo kitimas yra sunkai prognozuojamas, nes ji veikia adaptaciniai procesai ir laikas, t. y. vèluojanti reakcija ì rengima.

Tikslas — nustatyti šauliu rengimo ir parengtumo modeliu sasajas. Objektas — rengimo ir parengtumo modeliai.

2001 / 2002 ir 2002 / 2003 m. šaulè V. M. vykdè vienos alternatyvos eksperimenta. Buvo registruojami rengimo programu ir ju turinio bei dvieju šaudymo pistoletu pratimu rezultatu pokyčiai (testavimas), ieškoma rengimo ir parengtumo modeliu sqsajos (matematiné statistiné analizé). Lyginant 2001 / 2002 ir 2002 / 2003 m. rodiklius nustatyta, kad rengimo apimtys buvo padidintos. Rengimo turinį sudarè rengimas šaudant su šoviniu ir be jo.

Nustatyti šaulès rezultatu kitimo determinacijos koeficientai 2001 / 2002 ir 2002 / 2003 m. rengimo laikotarpiais leido teigti, kad pasiektam sportiniam parengtumui išlaikyti galejo turèti i̇takos rengimo programos dinamiškumas. Rezultatu pokyčiai buvo panašūs, lyginant 2001 / 2002 ir 2002 / 2003 m. laikotarpius, bet nustatyti atvirkštiniai ryšiai leidžia teigti, kad esminiais rengimo programos bruožais turètu būti specifiškumas ir individualumas. Rengimo modeli veikiantys skirtingu fiziniu krūviu elementai parengtumo modeli padarè dinamiška. Todèl norint, kad svarbiausiose varžybose bütu pasiekiama geriausiu asmeniniu rezultatu, reikètu parengti individualu šauliu rengimo ir parengtumo metamodelio algoritmq, numatyti rengimo bei parengtumo kaita. Algoritmo sandarq galètu sudaryti rengimosi trukme ir programos.

Raktažodžiai: šaudymas, sportininku rengimo valdymas, rengimo ir parengtumo modeliu sqsaja.

\section{IVADAS}

$\mathrm{S}$ porto mokslininkai (Mester, 1994; Martin, 1999; Hohmann et al., 2000; EdelmannNusser et al., 2002; Perl, 2004) tvirtina: nuolatinè krūvių ir rezultatų pokyčių analizè leidžia valdyti sportini parengtumą norint, kad per svarbiausias varžybas sportininkai pasiektų geriausių rezultatų.

Teigiama, kad pastaraisiais metais atletų rezultatu (parengtumo) gerẻjimą galèjo paveikti moks- linis šių elementų poveikio valdymas rengiant sportininkus (Meyers, 2002), bet J. R. Fitz-Clarke, R. H. Morton, E. W. Banister (1991) mano, jog sportininkų rengimas vis dar paremtas patirtimi ir intuicija. Jie siūlo rengimo poveiki išreikšti skaičiais ir ji optimizuoti, nes žmogaus parengtumo rodikliai suteikia tokia galimybę. Tai reiškia, kad analizuojant ryši (koreliaciją) tarp rengimo ir parengtumo imanoma numatyti sportinius rezultatus. 
Norint kad didelio meistriškumo šaulys pasiektu puikių rezultatu ypač svarbu gerai parengti ir veiksmingai taikyti kiekvieno rengimo etapo programa, atitinkančią šaulio individualumus (Kundert, 2003; Настенко, 2004; Рабинер, 2004).

Sportinio rengimo ciklą (Bompa, 1999; Perl, 2002), taip pat ir šaulių metini rengimo ciklą apibūdina įvairūs krūvio apimties, intensyvumo rodikliai - pratybų ir varžybų dienų skaičius per metus (Настенко, 2004), treniravimosi valandu skaičius per savaitę (Schreiber, 1997, 2001), šūvių skaičius per pratybas (Schreiber, 2004; Настенко, 2004; Груздев, 2005). Rengimo ir parengtumo sąsają bei kontroversiškumą apibūdina rengimo krūvių, sportininkų reakcijos i juos ir laiko dinamiškumas — didejjant krūviams, parengtumas laikinai blogejja, ir atvirkščiai (Mester, Perl, 2000; Perl, Mester, 2001; Perl, 2002; Mc Garry \& Perl, 2004; Perl \& Weber, 2004). Visgi reakcija ị krūvius yra labai individuali - $\mathfrak{i}$ tuos pačius krūvius sportininkai gali reaguoti visiškai skirtingai. Vadinasi, galima parengti tik individualų (Perl et al., 2002) sportininku rengimo ir parengtumo metamodelio algoritmą (Mester \& Perl, 2000; Perl, 2002).

Rengiant sportininkus svarbu numatyti tinkamą rengimo modeli, lemiantị sportinius rezultatus. J. Perl (2002) pažymi, kad sportininkų parengtumo kitimas yra sunkai prognozuojamas, nes ji veikia adaptaciniai procesai ir laikas, t. y. vẻluojanti reakcija į rengima.

Hipotezė: šaulių pistoleto rungties parengtumo modelio dinamiškumą lemia rengimo modelio - krūvių ir turinio - kitimo ypatumai.

Tyrimo tikslas - nustatyti šaulių rengimo ir parengtumo modelių sąsają.

Tyrimo objektas - rengimo ir parengtumo modeliai.

\section{Uždaviniai:}

1. Nustatyti 2001 / 2002 ir 2002 / 2003 m. rengimo bei parengtumo modelius.

2. Rasti rengimo ir parengtumo modelių sąsajas.

\section{METODAI}

1. 2001 / 2002 ir 2002 / 2003 m. buvo atliekamas šaulès V. M. (1997 m. Europos jaunimo pirmenybiu bronzos laimètojos, daugkartinès Lietuvos šaudymo čempionès), šaudančios pistoletu, rengimo programos vienos alternatyvos eksperimentas ir registruojamas jų turinio (rengimo dienų, pratybų, varžybų, poilsio dienų skaičius per metus, šūvių skaičius per metų pratybas ir varžybas (išskiriant Lietuvos ir tarptautines varžybas), šūviu skaičius pagal rengimo rūšis (technika, taktiką, integraluji rengimą), pratybų trukmé, šaudymo trukmè varžybose (išskiriant Lietuvos ir tarptautines), rengimo šaudant be šovinio trukmė) bei dviejų šaudymo pistoletu pratimų rezultatu kitimas (1 pav., 1 lent.). Pratimas PP-40 - tai šaudymas pneumatiniu pistoletu į taikini, esantị už 10 metrų. Rezultatui išaiškinti šaunama 40 šūvių. Pratimas MK $30+30$ - tai šaudymas į taikinius, esančius už 25 metrų. 30 šūvių šaunama i stovinti taikini, 30 - i pasirodanti.

Norint nustatyti šauliu sportinio parengtumo kitima, eksperimento metu buvo analizuojami varžybų rezultatai ir atliekamas testavimas kompiuterine iranga Rika Home Trainer programa (http://www.rika1.com).

2. Matematine statistine analize (aritmetinis vidurkis; standartinis nuokrypis; Pirsono koreliacijos koeficientas $\left(\mathrm{R}-\right.$ koreliacija; $\mathrm{R}_{\mathrm{PP}}-\mathrm{PP}-40$ pratimo rezultatu koreliacija, $\mathrm{R}_{\mathrm{mk}}-\mathrm{MK} 30+30$ pratimo rezultatu koreliacija), regresinè analize;; reikšmių skirtumo patikimumas nustatytas Stjudento $t$ kriterijų taikant priklausomoms imtims; reikšmingumo lygmuo $-\mathrm{p}<0,05$ ).

\section{REZULTATAI}

Rengiantis 2002 m. pasaulio ir 2003 m. Europos šaudymo čempionatams, buvo taikyti nevienodi krūviai. Lyginant 2001 / 2002 ir 2002 / 2003 m. rodiklius nustatyta, kad:

- padaugėjo rengimo dienų varžybų laikotarpiu;

- padidejjo rengimo dienų skaičius per savaitę;

- padaugèjo pratybų varžybų laikotarpiu;

- padidejo pratybų skaičius per savaitę;

- poilsio dienų skaičius sumažejo parengiamuoju, atsigavimo laikotarpiu, o varžybų metu padidejo;

- poilsio dienų skaičius per savaitę sumažèjo;

- startuota buvo dvigubai daugiau kartų;

- tarptautinėse varžybose startuota beveik keturis kartus daugiau;

- šūvių skaičius tarptautinėse varžybose padidèjo dvigubai;

- padidèjo šūvių skaičius varžybose (1 lent.). Rengimo programa tirta dviem aspektais - pagal:

- rengimo trukmę šaudant be šovinio (1 pav.);

- rengimą šaudant su šoviniu (bendrą šūvių skaičių (1 pav.) ir šūvių skaičiaus kaitą pagal rengimo rūšis (2 pav.)). 


\begin{tabular}{|c|c|c|}
\hline Rodikliai & 2001 / 2002 m. & 2002 / 2003 m. \\
\hline $\begin{array}{l}\text { Rengimo dienų skaičius per savaitę ( } \bar{X} \pm \mathrm{SD} \text { ) (su varžybomis) } \\
\text { Iš jų: parengiamuoju } \\
\quad \text { varžybų }\end{array}$ & $\begin{array}{l}3,54 \pm 1,45 \\
3,00 \pm 1,04 \\
5,00 \pm 0,91\end{array}$ & $\begin{array}{c}4,31 \pm 1,32 * \\
4,24 \pm 1,61 * * \\
4,38 \pm 1,73\end{array}$ \\
\hline $\begin{array}{l}\text { Treniravimosi dienų skaičius per savaitę ( } \bar{X} \pm \mathrm{SD}) \\
\text { Iš jų: parengiamuoju } \\
\quad \text { varžybų }\end{array}$ & $\begin{array}{l}3,14 \pm 1,23 \\
2,76 \pm 1,02 \\
4,15 \pm 1,14\end{array}$ & $\begin{array}{c}3,60 \pm 1,36 \\
3,76 \pm 1,41 * * \\
3,43 \pm 1,33\end{array}$ \\
\hline $\begin{array}{l}\text { Pratybų skaičius per savaitę }(\bar{X} \pm \mathrm{SD}) \\
\text { Iš jų: parengiamuoju } \\
\text { varžybų }\end{array}$ & $\begin{array}{l}4,14 \pm 2,04 \\
3,62 \pm 2,01 \\
5,31 \pm 1,65\end{array}$ & $\begin{array}{l}4,79 \pm 2,11 \\
4,67 \pm 2,08 \\
4,90 \pm 2,19\end{array}$ \\
\hline $\begin{array}{l}\text { Poilsio dienų skaičius per savaitę ( } \bar{X} \pm \mathrm{SD}) \\
\text { Iš jų: parengiamuoju } \\
\quad \text { varžybų }\end{array}$ & $\begin{array}{l}4,16 \pm 1,82 \\
4,19 \pm 1,25 \\
2,17 \pm 0,72\end{array}$ & $\begin{array}{c}3,61 \pm 2,04 \\
3,32 \pm 1,89 * \\
2,82 \pm 1,33\end{array}$ \\
\hline $\begin{array}{l}\text { Varžybų skaičius iš viso: } \\
\text { Iš jų: parengiamuoju } \\
\text { varžybų }\end{array}$ & $\begin{array}{c}18 \\
7 \\
11\end{array}$ & $\begin{array}{l}30 \\
10 \\
20\end{array}$ \\
\hline $\begin{array}{l}\text { Startų skaičius iš viso: } \\
\text { Iš jų: parengiamuoju } \\
\text { varžybų }\end{array}$ & $\begin{array}{c}20 \\
8 \\
12\end{array}$ & $\begin{array}{l}33 \\
12 \\
21\end{array}$ \\
\hline $\begin{array}{l}\text { Varžybų šūvių skaičius iš viso: } \\
\text { Iš jų: parengiamuoju } \\
\text { oficialių varžybų }\end{array}$ & $\begin{array}{l}2611 \\
1176 \\
1435\end{array}$ & $\begin{array}{l}2630 \\
1182 \\
1448\end{array}$ \\
\hline $\begin{array}{l}\text { Startuota tarptautinėse varžybose } \\
\text { Šūvių skaičius tarptautinėse varžybose }\end{array}$ & $\begin{array}{c}4 \\
350\end{array}$ & $\begin{array}{c}15 \\
886\end{array}$ \\
\hline
\end{tabular}

1 lentelè. $\mathbf{2 0 0 1 - 2 0 0 3 ~ m . ~ r o d i k l i a i ~ p a - ~}$ gal rengimo etapus $(\bar{X} \pm \mathrm{SD})$

Pastaba. Lyginant su atitinkamais 2001 / 2002 ir 2002 / 2003 m. rodikliais: * $-\mathrm{p}<0,05 ; * *-\mathrm{p}<0,01$.
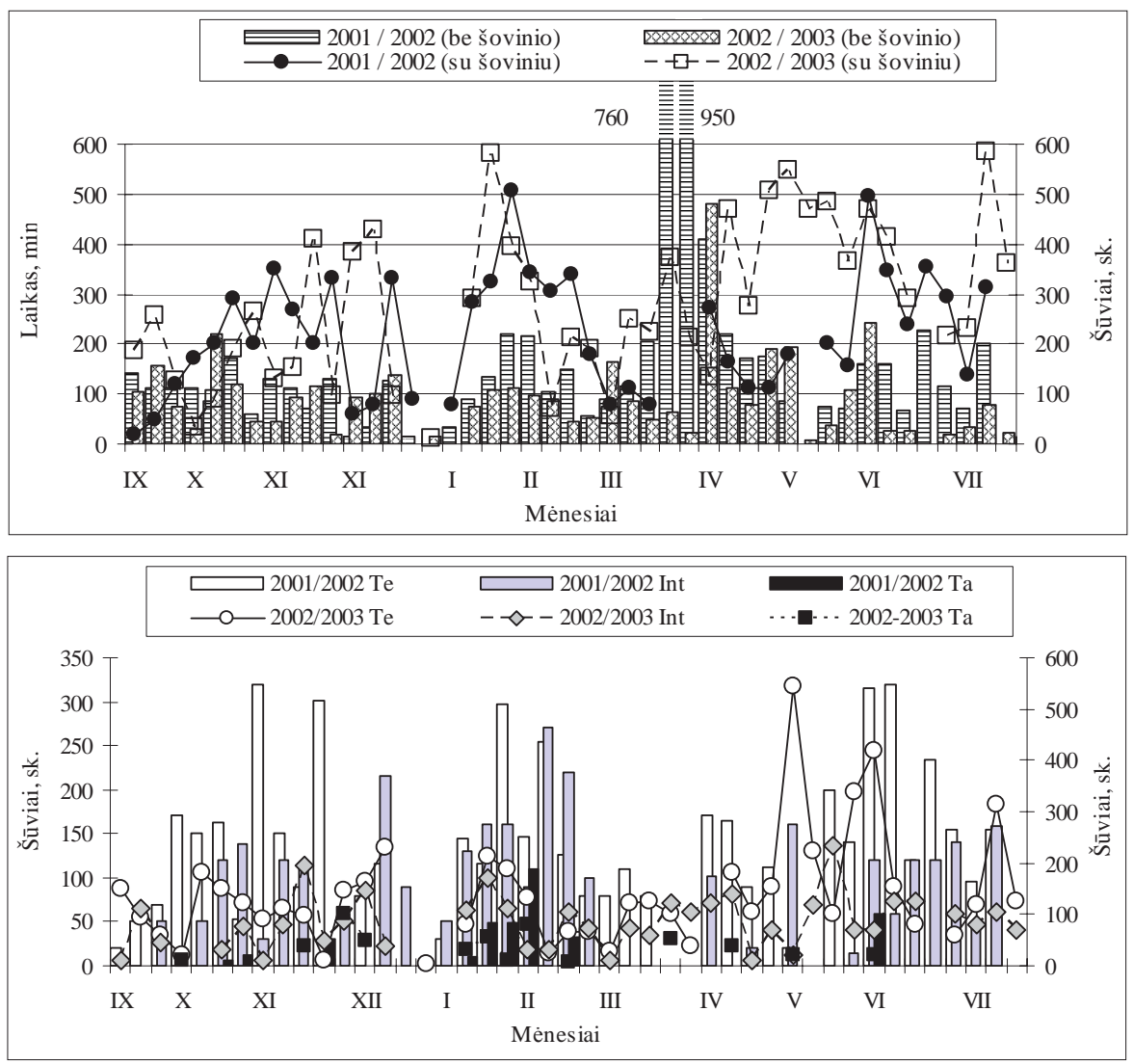

2 pav. Techninio (Te), taktinio (Ta) ir integraliojo (Int) rengimo rezultatų kitimas $2001-2003 \mathrm{~m}$. rengimo laikotarpiu

Nuo pirmų pratybǔ šūvių skaičius per abu rengimo laikotarpius buvo didinamas ir sausio mènesi pasiekè 500 šūviu per savaitę. Iki kovo mėnesio vidurio šūvių skaičius buvo mažinamas.

2001 / 2002 m. rengimo programoje didžiausias dėmesys skiriamas techniniam rengimui, per
1 pav. Rengimo šaudant su šoviniu ir be jo rezultatų kitimas 2001 2003 m. laikotarpiu pusę mažiau integraliajam, o taktiniam - net dešimt kartų mažiau nei integraliajam (2 pav.).

2002 / 2003 m. didžiausias dèmesys buvo skiriamas techniniam rengimui, per pusę mažiau integraliajam, o taktiniam — net dešimt kartų mažiau nei techniniam. 


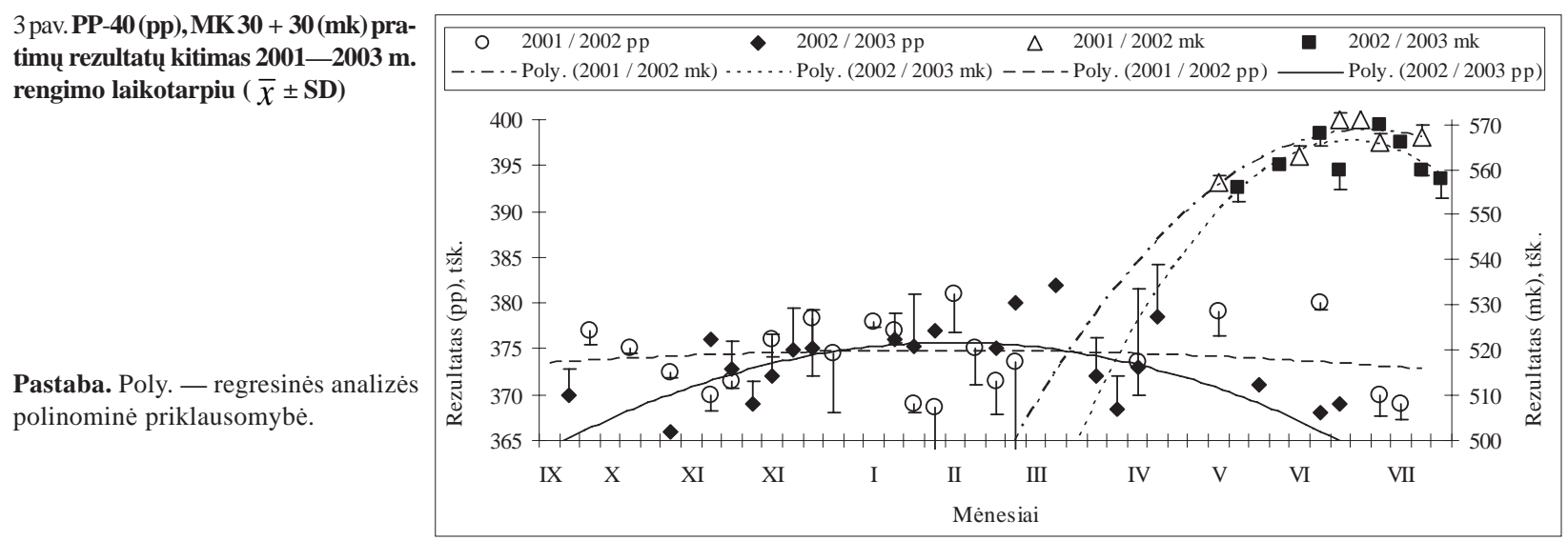

2001 / 2002 ir 2002 / 2003 m. laikotarpiais taikytos rengimo programos nevienodai paveike skirtingų pratimu rezultatus. MK $30+30$ pratimo rezultatai kito tolygiai, o PP-40 — skirtingai (3 pav.).

Nuo pirmo testavimo (2001 / 2002 m. rengimosi pradžia) sportininkès PP-40 pratimo rezultatas (377 taškai) iki lapkričio pradžios (surinkta 370 taškų testavimo metu) blogèjo, paskui iki sausio mėnesio pradžios gerèjo (378 taškai — testavimo metu; 376 taškai — „Polonia“ taurès varžybose) ir vẻl blogejjo iki balandžio mėnesio pradžios (374 taškai - testavimo metu). Pasaulio čempionato rezultatas (369 taškai) neatitiko Lietuvos varžybose pasiektų rezultatų. 2002 / 2003 m. PP-40 pratimo rezultatai nuo pirmo testavimo (370 taškai) šešis mėnesius gerejjo ir svarbiausiose Lietuvos varžybose (kovo mènesi) buvo geriausi (380 ir 382 taškai). Vèliau banguotai mažèjo ir pasaulio taurès etape pasiekè pirmo testavimo rezultata.

MK $30+30$ pratimo rezultatai iki Lietuvos svarbiausių varžybų (Lietuvos šaudymo čempionato) gerèjo: 2001 / 2002 m. - 571 taškai; 2002 / 2003 m. - 570 taškai, tačiau tarptautinèse varžybose (2002 m. pasaulio šaudymo čempionate, 2003 metu pasaulio taurès etapuose) buvo blogiausi (2001 / 2002 m. - 567 taškai; 2002 / 2003 m. - 558 taškai) (3 pav.).

\section{REZULTATŲ APTARIMAS}

2001 / 2002 m. banguotai kitę PP-40 pratimo rezultatai (regresinès analizès polinominè priklausomybė $y=-0,0036 x^{2}+0,1449 x+373,28$; determinacijos koeficientas $\mathrm{R}^{2}=0,022$ ) ir to paties pratimo 2002 / 2003 m. šešis mènesius pamažu gerejję rezultatai (regresinès analizės polinominè priklausomybé $\mathrm{y}=-0,0293 \mathrm{x}^{2}+1,224 \mathrm{x}+362,92$; determinacijos koeficientas $\mathrm{R}^{2}=0,4036$ ) rodo parengtumo dinamiškumą ir nelinijinę rengimo bei parengtumo modelių priklausomybę (Mester, Perl, 2000; Perl \& Mester, 2001; Perl, 2002; Mc Garry, \& Perl, 2004; Perl, Weber, 2004). Visgi sąsaja tarp viso 2001 / 2002 ir 2002 / 2003 m. ciklų PP-40 pratimo rengimo ir parengtumo rodikliu nenustatyta.

MK $30+30$ pratimo rezultatų kaita $2001 / 2002 \mathrm{~m}$. (regresinès analizès polinominè priklausomybè $\mathrm{y}=-0,2277 \mathrm{x}^{2}+18,824 \mathrm{x}+179$, 69; determinacijos koeficientas $\mathrm{R}^{2}=0,7883$ ) ir 2002 / 2003 m. (regresinès analizès polinominè priklausomybè $y=-0,3682 x^{2}+29,818 x-37,291$; $\mathrm{R}^{2}=0,576$ ) (geriausių rezultatų buvo pasieka Lietuvos šaudymo čempionate, blogiausių — tarptautinèse varžybose) galėjo paveikti rengimo programos dinamiškumas (Mester, Perl, 2000; Perl \& Mester, 2001; Perl, 2002; Masalskyté, Skarbalius, 2003; Mc Garry, \& Perl, 2004; Perl, Weber, 2004).

Nenustatytas šaulès V. M. PP-40 pratimo rezultatu ir makrociklo rengimo programos koreliacinis ryšys atitinka J. Mester ir bendraautoriu (2000) tyrimo išvadas: tarp krūvių ir parengtumo rodiklių sąsajos nėra.

Nustatyta silpna koreliacija $(\mathrm{R}=0,335)$ tarp MK $30+30$ pratimo $2001 / 2002$ m. rezultatų ir rengimo šaudant be šovinio kitimo bei esminè atvirkštinè $(\mathrm{R}=-0,442)$ - tarp $2002 / 2003 \mathrm{~m}$. rezultatų ir šūvių skaičiaus kitimo. PP-40 ir MK $30+30$ pratimų rezultatų kaita buvo panaši, lyginant 2001 / 2002 ir 2002 / 2003 m. laikotarpiu rezultatus, bet nustatytas atvirkštinis ryšys - esminis $\left(\mathrm{R}_{\mathrm{pP}}=-0,416\right)$ ir stiprus $\left(\mathrm{R}_{\mathrm{mk}}=-0,655\right)$. Tai lèmé 2001 / 2002 m. pirmoje rengimo programos dalyje vyravęs rengimas šaudant su šoviniu, o antroje - šaudant be šovinio. 2002 / 2003 m. rengimo pradžioje didesnis demesys buvo skiriamas bendrajam rengimui, t. y. rengimo laikui be 
šovinio, o vèliau — specifiniam (didinamas šūviu skaičius). 2002 / 2003 m. pasiekti geresni rezultatai patvirtina nuostatas, kad esminiais rengimo programos bruožais turètų būti specifiškumas ir individualumas (Tuennemann, 1996; Müller et al., 2000; Gulbinskienè, Skarbalius, 2005).

Sportininkų pasiekti rezultatai aukščiausio rango varžybose yra svarbiausias jų parengtumo rodiklis (Mester, 1994; Bompa, 1999; Martin, 1999; Tuennemann, 1996). Psichinis parengtumas yra sportinio parengtumo sudètinè dalis (Bompa, 1999), ypač reikšminga šauliui, kuris nuolat veikiamas streso, ir jo rezultatas priklauso nuo centrinės nervų sistemos veiklos. Galima daryti prielaida, kad šaulei nepavyko pasiekti planuotu rezultatų dèl to, kad ji turèjo statistiškai reikšmingą ( $<00,001)$ tarptautinių varžybų patirti (Masalskytė, Skarbalius, 2003).
Galima teigti, kad ịvertinus keleriu metų rengimo bei parengtumo modelių tarpusavio sąsajos ypatumus, būtų imanoma numatyti rengimo, parengtumo kaitą ir svarbiausiose varžybose pasiekti geriausių asmeninių rezultatų. Tai atitiktų I. Balyi ir A. Marion (1998) atletu sportinio rengimo rekomendacijas: įvertinus ankstesnių metų rengimo programas, jų pagrindu modeliuoti kitas.

\section{IŠVADA}

Dèl rengimo ir parengtumo modelių dinamiškumo net kelerių metų teoriškai pagrịsta ir praktiškai patikrinta rengimo programa bei pasiekti sportiniai rezultatai vis dèlto nesudarytų patikimų garantijų kryptingai valdyti šaulio rengimą ir prognozuoti tikslius rezultatus (Mester, 1994; Hohmann et al., 2000; Mester, Perl, 2000; Edelmann-Nusser et al., 2002).

\section{LITERATŪRA}

Balyi, I., Marion, A. (1998). Designing an Annual Training and Competition Plan: a Step by Step Approach. Coaching Association of Canada. Prieiga per interneta: http://www. targetshooting.ca/docs/DesigningAnAnnualTraining.pdf

Bompa, O. T. (1999). Periodization: Theory and methodology (4th edition). Human Kinetics.

Edelmann-Nusser, J., Hohmann, A. \& Henneberg, B. (2002). Modeling and Prediction of Competitive Performance in Swimming Upon Neural Networks. European Journal of Sport Science, 2 (2), 1-10.

Fitz-Clarke, J. R., Morton, R. H., Banister, E. W. (1991). Optimizing athletic performance by influence curves. Journal of Applied Physiology, 71 (3), 1151-1158.

Gulbinskienė, V., Skarbalius, A. (2005). Individual shooting training model of 27 weeks preparation period. Faculty of Exercise and Sport Sciences University of Bologna and University of Bologna Sport Center: proceeding of the IASK 9 th International Sport Kinetics 2005 Conference: "Scientific Fundaments of Human Movement and Sport Practice", 151-153.

Hohmann, A., Edelmann-Nusser, J., Henneberg, B. (2000). A Nonlinear Approach to the Analysis \& Modeling of Training \& Adaptation in Swimming. Reproduced from ISBS Swimming 2000 Web Site. Prieiga per internetą: http://www.coachesinfo.com/category/swimming/152/

Kundert, G. (2003). Marcel Buerge — shooter of year 2002. ISSF NEWS international shooting sport, 2, 21-23.

Martin, D. (1999). International Development and Training Strategies in High Peak Performance. Prieiga per interneta: http://www.uni-saarland.de/fak5/swi-eu/eng/exp_hear/index.htm

Masalskytė, V., Skarbalius, A. (2003). Šaulès parengtumo kitimas rengiantis 2003 metu pasaulio taurès varžyboms.
Ugdymas. Kūno kultūra. Sportas, 5 (50), 33-37.

Mc Garry, T. \& Perl, J. (2004). Models of sports contests - Markov processes, dynamical systems and neural networks. In M. Hughes \& I. M. Franks (Eds.), Notational Analysis of Sport (pp. 227-242). London and New York: Routledge.

Mester, J. (1994). Elite sport: The Present Level of Scientific Research - Legitimation, Designs and Methods. Sport Sciences in Europe 1993: Curent and Future Perspectives. Aachen: Meyer \& Meyer Verlag. P. 245-259.

Mester, J. \& Perl, J. (2000). Grenzen der Anpassungund Leistungsfähigkeit aus systemischer SichtZeitreihenanalyse und ein informatisches Metamodell zur Untersuchung physiologischer Adaptionsprozesse. Leistungssport, 30 (1), 43-51.

Mester, J., Perl, J., Niessen, M., Hartmann, U. (2000). Time Series Analyses and Metamodels for Analyses of Physiological Adaptation. In J. Avela, P. V. Komi, J. Komulainen, Proceedings of the 5th Annual Congress of the European College of Sport Science (p. 75). Jyväskulä: University of Jyväskulä.

Meyers, M. C. (2002). Improving Athletic Performance: The Marriage of Sports Science \& Coaching. Coaches' information service. Prieiga per internetą: http://www.coachesinfo.com/article/10/\#further informationexternalsources Müller, E., Benko, U., Raschner, C., Schwameder, H. (2000). Specific fitness training and testing in competitive sports. Medicine Science and Sports Exercise, 1 (32), 216-220.

Perl, J. (2002). Adaptation, Antagonism and System Dynamics. In G. Ghent, D. Kluka \& D. Jones, Perspektives - The Multidisciplinary Series of Physical Education an Sport Science, 4, 105-125. Oxford: Meyer \& Meyer Sport. 
Perl, J., Dauscher, P. \& Hawlitzky, M. (2002). On the Long-Term Behaviour of the Performance-Potential Metamodel PerPot. Abstract for the 7th Annual Congress of the European College of Sport Science. Athens.

Perl, J. \& Mester, S. (2001). Modellgestützte Analyse und Optimierung der Wechselwirkung zwischen Belastung und Leistung. Leistungssport, 31 (2), 54-62.

Perl, J. \& Weber, K. (2004). A Neural Network approach to pattern learning in sport. International Journal of Computer Science in Sport, 3 (1), 67-70.

Schreiber, W. (2001). Luna Tao — "I have a lot of time to make my dreams come true...”. ISSF NEWS International Shooting Sport, (1), 12-13.

Schreiber, W. (2004). Martin Tenk - on the way to Athens - Tenk - 2003 shooter of the year. ISSF NEWS International Shooting Sport, (4), 22-24.
Schreiber, W. (1997). Roberto Di Dona — "Sport Shooting Is My Life”. ISSF NEWS International Shooting Sport, (3), 13-19.

Tuennemann, H. (1996). Developments of Means \& Training Methods in Combats. The Second Post Olympic International Symposium. The Process of Training and Competition in View of the 96 Atlanta Games (pp. 5364). Netan: Wingate Institute.

Груздев, А. (2005). Один день олимпийского чемпиона Михаила Неструева. Калашников, 1. Prieiga per internetą: http://shooting-russia.ru/smi.html?

Настенко, Г. (2004). Как попасть в „яблочко“. Труд, 186, 8.

Рабинер, И. (2004). Михаил Неструев: когда-то бросил стрельбу на пять лет. Спорm-Экспрес, 189, 13.

\title{
ONE YEAR TRAINING AND PERFORMANCE INTERACTION PECULIARITIES OF PISTOL SHOOTING
}

\author{
Vaida Gulbinskienė, Antanas Skarbalius \\ Lithuanian Academy of Physical Education, Kaunas, Lithuania
}

\begin{abstract}
The high performance shooters' results depend on training program which should be not only adequate for shooters individuality but also well prepared and effectively applied on every training stage. The permanent analysis of the training loads and results variation is allowed to manage the sport performance. But the variation of the sport performance is hardly forecasted because it depends on the time delay of the adaptation.

The aim — the interaction between the training and performance models. The object — the training and performance models.

The shooter V. M. pursued one alternative experiment in the year 2001 / 2002 and 2002 / 2003. The variation of the training program content, the variation of the two pistol shooting exercises results (testing) were registered and the interaction between the training and the performance models (mathematical statistics analyzes) was determined. Different training loads on 2001 / 2002 and 2002 / 2003 year were estimated. The training volume consists of the training time with a shot and without a shot.

The shooter's V. M. results variation in the year 2001 / 2002 and 2002 / 2003 allowed to confirm that influence on the results variation had the training program dynamic variation. The results variations were similar in 2001 / 2002 and 2002 / 2003 years but reverse relations between them allowed to confirm the essential features are the specificity and the individuality. The training load items provoke the performance model dynamism especially in response to the training loads and the time needed for it. It is possible to prepare the individual shooters' training and performance algorithm of the Meta model and it allows to provide the variation of the sport training and the sport performance. The algorithm may be composed of the training time and the program content (training with a shot and without it).
\end{abstract}

Keywords: shooting, athletes training management, training and performance models interaction.

Gauta 2006 m. vasario 10 d.

Received on February 10, 2006

Priimta 2006 m. gegužès 25 d.

Accepted on May 25, 2006
Vaida Gulbinskienè

Lietuvos kūno kultūros akademija

(Lithuanian Academy of Physical Education)

Sporto g. 6, LT-44221 Kaunas

Lietuva (Lithuania)

Tel +37061458151

E-mail v.gulbinskiene@lkka.lt 